Published in final edited form as:

Epidemiology. 2011 January ; 22(1): 15-17. doi:10.1097/EDE.0b013e3181fe1fbe.

\title{
Childhood Abuse and Fibroids
}

Donna Baird ${ }^{1}$ and Lauren Wise ${ }^{2,3}$

${ }^{1}$ National Institute of Environmental Health Sciences, NIH, Research Triangle Park, NC

2 Boston University School of Public Health, Boston, MA

${ }^{3}$ Slone Epidemiology Center, Boston, AM

There is growing evidence that adults who have experienced childhood abuse are more likely to have health problems than those without these experiences. Sequelae can be behavioral (e.g., substance abuse), mental-health-related (e.g., depression), as well as physical-health-related (e.g., cardiovascular disease).$^{1-4}$ The public health consequences are sobering given the numbers exposed. Even with probable under-reporting, prevalence estimates from the U.S. and Europe exceed 25\%. ${ }^{2,5}$ Adverse sequelae may be mitigated by social support and healthy coping. ${ }^{6}$ In this issue Boynton-Jarrett et al. ${ }^{7}$ add uterine leiomyoma (fibroids) to the list of possible adverse outcomes associated with childhood abuse. They also find a tendency for an emotionally-supportive relationship to mitigate these effects.

As Boynton-Jarrett and colleagues ${ }^{7}$ point out, fibroids are a major public-health issue. Fibroids have been the leading indication for hysterectomy in the U.S. for decades. ${ }^{8,9}$ Costs for both inpatient and outpatient medical management of fibroid-associated symptoms are high. ${ }^{10,11}$ The direct morbidity burdens fall on symptomatic women.

Though still in its early stages, epidemiologic research on fibroids has made major advances in the last two decades. This is due largely to a shift from study of surgical cases (which include only small, non-representative subsamples of all women with fibroids) to studies that screen women with ultrasound, or studies such as the Nurses' Health Study and the Black Women's Health Study that prospectively identify incident cases based on selfreported clinical diagnoses.

Newer studies still have limitations. The primary limitation of the large prospective cohort studies is misclassification of case status. Many women with fibroids are not clinically diagnosed. This occurs even if diagnoses are reported accurately and the diagnostic tools for detection of disease are valid - as has been demonstrated for ultrasound diagnosis of fibroids. ${ }^{12}$ Ultrasound screening in premenopausal women aged 35-49 years who had never been diagnosed with fibroids revealed fibroids in $51 \% .{ }^{13}$ Nearly all diagnosed women are a

Address for Correspondence: Donna Baird, National Institute of Environmental Health Sciences, NIH, PO Box 12233, Research Triangle Park, NC 27709; baird@ niehs.nih.gov; phone: 919 541-2786.

Publisher's Disclaimer: This is a PDF file of an unedited manuscript that has been accepted for publication. As a service to our customers we are providing this early version of the manuscript. The manuscript will undergo copyediting, typesetting, and review of the resulting proof before it is published in its final citable form. Please note that during the production process errors may be discovered which could affect the content, and all legal disclaimers that apply to the journal pertain. 
mix of those who sought care for symptoms and those discovered to have fibroids during a routine examination. The former are more likely to have severe disease; the latter are more likely to have mild disease. However, undiagnosed cases cannot be assumed to have more mild disease, because even women with severe disease may tolerate the symptoms. In one study that screened for fibroids, diagnosed and undiagnosed cases were equally likely to have symptoms of bleeding, after adjustment for fibroid size. ${ }^{14}$

How might such outcome misclassification affect the association reported by BoyntonJarrett et al. ${ }^{7}$ ? Several studies have linked history of abuse with chronic pelvic pain ${ }^{15}$ and increased health-care utilization. ${ }^{16}$ Women with a history of abuse may be more likely to have ultrasound examinations and thus increased fibroid diagnoses, even if the history of abuse had no real etiologic relationship with fibroid development. Control for recent pelvic exam would not control for differential referral for ultrasound.

Another concern is potential selection bias from the standard prospective-cohort analysis strategy of excluding women with previously-diagnosed fibroids at baseline.

Women with early onset will tend to be over-represented in the excluded group. It would have been interesting to see results from an analysis of the prevalent cases at the beginning of follow-up, or to see whether the association in the prospective analysis was stronger for diagnoses by age 35 (early onset). The latter analytic strategy has been used in other investigations of risk factors for fibroids using prospective cohort data. ${ }^{17}$

Boynton-Jarrett and colleagues ${ }^{7}$ are the first to report increased risk of fibroids for women who experience early-life abuse, but other reports ${ }^{18,19}$ have suggested a possible association between stress and fibroid development, and these bolster the plausibility of the findings reported in this issue. A recent cross-sectional study ${ }^{18}$ found a positive association between fibroid prevalence and the number of major life events, as well as "stress intensity." In the Black Women's Health Study, perceived racial discrimination, (a chronic stressor) was positively associated with fibroid risk. The association was weaker among women with higher coping skills, ${ }^{19}$ suggesting that social and emotional support may buffer the impact of stress on fibroid risk. This is similar to the effect of an emotionally-supportive relationship in childhood found by Boynton-Jarrett et al.

New research on epigenetic changes shows that early-life exposures can have long-term functional affects. ${ }^{20}$ Ongoing stress could also be important. The hormones estrogen and progesterone are mediators of fibroid development. ${ }^{21,} 22$ In the classic fight/flight response, stress can down-regulate the hypothalamic/pituitary support of ovarian steroids, but stress can also up-regulate adrenal progesterone. ${ }^{23,}{ }^{24}$ Stress-related increases in progesterone have been demonstrated in Cebus monkeys ${ }^{25}$ and in an experimental study of postmenopausal women. ${ }^{24}$ Granulosa-cell tissue-culture studies suggest that there may also be situations in which ovarian steroid secretion is increased rather than decreased. ${ }^{26}$ Moreover, various growth factors, cytokines, and matrix metalloproteinases involved in fibroid growth can be upregulated by stress hormones. ${ }^{23,}{ }^{24}$ Stress can also lead to adverse health-related behaviors, such as physical inactivity, heavy alcohol consumption, and poor eating habits, and these may increase fibroid development. ${ }^{27}$ 
Though not yet available, non-invasive medical treatments for fibroids are under development. When they become available, they are likely to be most effective early in the disease process. Identifying high-risk groups for systematic ultrasound screening will be important. Future fibroid research must provide this guidance. The two large cohort studies that have provided much new knowledge of fibroid epidemiology (the Nurses' Health Study and the Black Women's Health Study) will be aging out of fibroid research in the next decade. Their youngest participants are now 46 and 36, respectively. Many participants are already postmenopausal, a time when fibroids tend to shrink. Perhaps the mothers in the large pregnancy cohorts in the U.S. and Europe could be tapped for fibroid research. As women's children are followed, the health of the mothers could also be followed. Outcome data collection in large prospective-cohort studies can easily include clinical diagnosis (yes/no) and type of diagnosis (ultrasound, surgery, or pelvic exam), as well as a question about the circumstances of diagnosis (seeking help for symptoms vs. findings at routine health exam), as is currently being done in the Black Women's Health Study. Finally, it is time for a prospective study that recruits young women before they begin to develop fibroids. Periodic ultrasound screening during follow-up can then identify cases closer to the time of true disease onset. Data from these future studies will shed further light on the relationship of childhood abuse and uterine fibroid development, and the mechanisms by which such an association might arise.

\section{Biographies}

DONNA BAIRD is a principal investigator in the Epidemiology Branch at the National Institute of Environmental Health Sciences, NIH. She conducted the first large study of fibroids that used ultrasound screening. She has interest in vitamin D as a potential protective factor.

LAUREN WISE is Associate Professor at Boston University School of Public Health and Senior Epidemiologist at the Slone Epidemiology Center. She is principal investigator of NIH-funded studies examining dietary and genetic determinants of fibroids in the Black Women's Health Study.

\section{References}

1. Wegman HL, Stetler C. A meta-analytic review of the effects of childhood abuse on medical outcomes in adulthood. Psychosom Med. 2009; 71:805-12. [PubMed: 19779142]

2. Gilbert R, Widom CS, Browne K, Fergusson D, Webb E, Janson S. Burden and consequences of child maltreatment in high-income countries. Lancet. 2009; 373:68-81. [PubMed: 19056114]

3. Felitti VJ, Anda R, Nordenberg D, et al. The Relationship of Childhood Abuse and Household Dysfunction to Many of the Leading Causes of Death in Adults: The Adverse Childhood Experiences (ACE) Study. Amer J Prev Med. 1998; 14:245-58. [PubMed: 9635069]

4. Goodwin RD, Stein MB. Association between childhood trauma and physical disorders among adults in the United States. Psychol Med. 2004; 34:509-20. [PubMed: 15259836]

5. Dube SR, Cook ML, Edwards VJ. Health-related outcomes of adverse childhood experiences in Texas, 2002. Prev Chronic Dis. 2010; 7:A52. [PubMed: 20394691]

6. Feder A, Nestler EJ, Charney DS. Psychobiology and molecular genetics of resilience. Nat Rev Neurosci. 2009; 10:446-57. [PubMed: 19455174] 
7. Boynton-Jarrett R, Rich-Edwards JW, Jun H-J, Hibert EN, Wright RJ. Abuse in childhood and risk of uterine leiomyoma: the role of emotional support in biological resilience. Epidemiology. 2011; 22: $\mathrm{xxx}-\mathrm{xxx}$.

8. Wilcox LS, Koonin LM, Pokras R, Strauss LT, Xia Z, Peterson HB. Hysterectomy in the United States, 1988-1990. Obstet Gynecol. 1994; 83:549-55. [PubMed: 8134065]

9. Farquhar CM, Steiner CA. Hysterectomy rates in the United States 1990-1997. Obstet Gynecol. 2002; 99:229-34. [PubMed: 11814502]

10. Flynn M, Jamison M, Datta S, Myers E. Health care resource use for uterine fibroid tumors in the United States. Am J Obstet Gynecol. 2006; 195:955-64. [PubMed: 16723104]

11. Hartmann KE, Birnbaum H, Ben-Hamadi R, et al. Annual costs associated with diagnosis of uterine leiomyomata. Obstet Gynecol. 2006; 108:930-7. [PubMed: 17012456]

12. Dueholm M, Lundorf E, Hansen ES, Ledertoug S, Olesen F. Accuracy of magnetic resonance imaging and transvaginal ultrasonography in the diagnosis, mapping, and measurement of uterine myomas. Am J Obstet Gynecol. 2002; 186:409-15. [PubMed: 11904599]

13. Baird DD, Dunson DB, Hill MC, Cousins D, Schectman JM. High cumulative incidence of uterine leiomyoma in black and white women: ultrasound evidence. Am J Obstet Gynecol. 2003; 188:100-7. [PubMed: 12548202]

14. Wegienka G, Baird DD, Hertz-Picciotto I, Harlow SD, Hartmann KE. Uterine leiomyomata (fibroids): are bleeding symptoms more likely to be reported after diagnosis? J Clin Epidemiol. 2004; 57:318-20. [PubMed: 15066693]

15. Paras ML, Murad MH, Chen LP, et al. Sexual Abuse and Lifetime Diagnosis of Somatic Disorders: A Systematic Review and Meta-analysis. JAMA. 2009; 302:550-61. [PubMed: 19654389]

16. Bonomi AE, Anderson ML, Rivara FP, et al. Health care utilization and costs associated with childhood abuse. J Gen Intern Med. 2008; 23:294-9. [PubMed: 18204885]

17. Wise LA, Palmer JR, Harlow BL, et al. Risk of uterine leiomyomata in relation to tobacco, alcohol and caffeine consumption in the Black Women's Health Study. Hum Reprod. 2004; 19:1746-54. [PubMed: 15218005]

18. Vines AI, Ta M, Esserman DA. The Association Between Self-Reported Major Life Events and the Presence of Uterine Fibroids Women's Health Issues. 2010; 20:294-8.

19. Wise LA, Palmer JR, Cozier YC, Hunt MO, Stewart EA, Rosenberg L. Perceived Racial Discrimination and Risk of Uterine Leiomyomata. Epidemiology. 2007; 18:747-57. [PubMed: 17917606]

20. Champagne FA. Epigenetic influence of social experiences across the lifespan. Dev Psychobiol. 2010; 52:299-311. [PubMed: 20175106]

21. Rein MS, Barbieri RL, Friedman AJ. Progesterone: a critical role in the pathogenesis of uterine myomas. Am J Obstet Gynecol. 1995; 172:14-8. [PubMed: 7847524]

22. Sozen I, Arici A. Cellular Biology of Myomas: Interaction of Sex Steroids with Cytokines and Growth Factors. Obstet Gynecol Clinics of North America. 2006; 33:41-58.

23. Ferin M. Clinical review 105: Stress and the reproductive cycle. J Clin Endocrin Metab. 1999; 84:1768-74.

24. Puder JJ, Freda PU, Goland RS, Ferin M, Wardlaw SL. Stimulatory effects of stress on gonadotropin secretion in estrogen-treated women. J Clin Endocrin Metab. 2000; 85:2184-8.

25. Lahoz MM, Nagle CA, Porta M, Farinati Z, Manzur TD. Cortisol response and ovarian hormones in juvenile and cycling female Cebus monkeys: effect of stress and dexamethasone. Am J Primatol. 2007; 69:551-61. [PubMed: 17177312]

26. Kornya L, Bodis J, Koppan M, Tinneberg HR, Torok A. Modulatory effect of acetylcholine on gonadotropin-stimulated human granulosa cell steroid secretion. Gynecol Obstet Invest. 2001; 52:104-7. [PubMed: 11586037]

27. Laughlin SK, Schroeder JC, Baird DD. New directions in the epidemiology of uterine fibroids. Semin Reprod Med. 2010; 28:204-17. [PubMed: 20414843] 